\title{
Cessation of methotrexate and a small intestinal resection provide a good clinical course for a patient with a jejunum perforation induced by a methotrexate- associated lymphoproliferative disorder: a case report
}

Masahiro Nomura, Ryusuke Sumiya * (D), Hayato Ono, Takeshi Nagai, Keigo Kumazawa, Atsushi Shimizu, Daisuke Endo and Nobuyoshi Aoyanagi

\begin{abstract}
Background: Methotrexate (MTX) is a frequently used drug in the treatment of rheumatoid arthritis (RA), but occurrences of lymphoproliferative disorders (LPD) have been reported in patients undergoing an MTX regimen. Almost half of the patients with methotrexate-associated lymphoproliferative disorders (MTX-LPD) have extranodal lesions; moreover, although extremely rare, digestive tract perforations resulting from the extranodal lesions of MTXLPD have also been reported.

Case presentation: We describe the case of an 81-year-old woman with RA who had been prescribed MTX at 6 mg per week for the past 11 years. She was admitted to our hospital with occasional abdominal pain and was first diagnosed with enteritis. Her abdominal pain did not improve, and a computed tomography scan showed abdominal effusion and free air in the abdominal cavity. She was diagnosed with a digestive tract perforation and underwent emergency surgery. The perforation site was identified in the jejunum, and she underwent small intestinal resection around the perforated region. The pathological findings showed an ulcer in the jejunum and infiltration of large atypical lymphocytes around the perforated region. An immunohistochemical examination revealed the expression of a cluster of differentiation 20 and latent membrane protein 1. Considering the patient's history of RA treated with MTX, she was diagnosed as having Epstein-Barr virus (EBV)-related MTX-LPD with a histological diagnosis of EBVMCU. MTX was discontinued after the surgery, and her soluble interleukin-2 receptor (sIL-2R) levels had returned to normal 1 year later. She has had a good course for the 2 years since surgery and remains asymptomatic with no recurrence of MTX-LPD, as confirmed by the sIL-2R levels.

* Correspondence: rsumiya@hosp.ncgm.go.jp

Department of Surgery, Kohnodai Hospital, National Center for Global Health and Medicine, 1-7-1 Konodai, Ichikawa-shi, Chiba 272-8156, Japan

(c) The Author(s). 2021 Open Access This article is licensed under a Creative Commons Attribution 4.0 International License, which permits use, sharing, adaptation, distribution and reproduction in any medium or format, as long as you give appropriate credit to the original author(s) and the source, provide a link to the Creative Commons licence, and indicate if changes were made. The images or other third party material in this article are included in the article's Creative Commons licence, unless indicated otherwise in a credit line to the material. If material is not included in the article's Creative Commons licence and your intended use is not permitted by statutory regulation or exceeds the permitted use, you will need to obtain permission directly from the copyright holder. To view a copy of this licence, visit http://creativecommons.org/licenses/by/4.0/ The Creative Commons Public Domain Dedication waiver (http://creativecommons.org/publicdomain/zero/1.0/) applies to the data made available in this article, unless otherwise stated in a credit line to the data. 


\begin{abstract}
(Continued from previous page)
Conclusion: We experienced a rare case of the jejunum perforation induced by MTX-LPD. Since only a few cases have been reported of a patient with small intestinal perforation induced by MTX-LPD, further research is necessary to evaluate the clinicopathological features of MTX-LPD. The patient had disease remission after surgery and by discontinuing MTX treatment; our case did not require chemotherapy. EBV-positive patients, especially those with a pathological presentation of EBVMCU, could have a higher likelihood of remission, which could have been a factor in the present case.
\end{abstract}

Keywords: Methotrexate, Lymphoproliferative disorder, Intestinal perforation, Jejunum, Epstein-Barr virus, Case report, Epstein-Barr virus-positive mucocutaneous ulcer, EBVMCU

\section{Background}

Methotrexate (MTX) is a key drug in the treatment of rheumatoid arthritis (RA), and one of the adverse effects can be lymphoproliferative disorders (LPD). However, the incidence of methotrexate-associated lymphoproliferative disorders (MTX-LPD) is extremely rare, reported as $0.00168 /$ person-year [1]. MTX-LPD was categorized with other iatrogenic immunodeficiency-associated lymphoproliferative disorders (Oii-LPD) in the revised 2017 fourth edition of the World Health Organization's (WHO) Classification of Tumours of Haematopoietic and Lymphoid Tissues [2]. Almost half of the patients with MTX-LPD had extranodal lesions associated with the brain, lungs, kidneys, liver, and bone marrow [3]. Extranodal lesions in the digestive tract are rare, but a few cases of patients with small intestinal perforations resulting from extranodal lesions of MTX-LPD are reported [4]. Although chemotherapy should be administered to patients who have progressive LPD, spontaneous LPD regression after MTX cessation without chemotherapy is often achieved in up to half the cases of MTX-LPD after ending MTX treatment [5]. Here, we describe a rare case of a patient with a jejunum perforation induced by MTX-LPD who underwent a partial small-intestine resection and had a remission after cessation of MTX.

\section{Case presentation}

An 81-year-old woman was admitted to our hospital due to occasional abdominal pain. She had a medical history of RA for the previous 14 years, hypertension, and nonalcoholic fatty liver disease. To control her RA, she had been taking MTX (6 mg per week) and prednisolone (5 $\mathrm{mg} / 2.5 \mathrm{mg}$ every other day) for the past 11 years. A physical examination revealed pain throughout her abdomen with rebound tenderness on the left side; however, she had no fever, and her abdomen was soft and flat.

Laboratory findings included a white blood cell count, 4400/ $\mu \mathrm{L}$ (reference range, 3300-8600/ $\mu \mathrm{L}$ ); lymphocyte count, $572 / \mu \mathrm{L}$ (13\%) (reference range, 18-50\%); hemoglobin, $12.8 \mathrm{~g} / \mathrm{dL}$ (reference range, 11.6-14.8 g/dL); platelet count, 240,000/ $\mu \mathrm{L}$ (reference range, 158,000$348,000 / \mu \mathrm{L}$ ); albumin, $3.6 \mathrm{~g} / \mathrm{dL}$ (reference range, 4.1-5.1 $\mathrm{g} / \mathrm{dL}$ ); lactate dehydrogenase, $296 \mathrm{U} / \mathrm{L}$ (reference range, 124-222 U/L); and C-reactive protein, $1.91 \mathrm{mg} / \mathrm{dL}$ (reference range, $0.00-0.14 \mathrm{mg} / \mathrm{dL}$ ). An abdominal computed tomography $(\mathrm{CT})$ scan showed small-intestine edema, and her initial diagnosis was enteritis.

Antibiotic therapy was administered on the second day of her hospital stay because her white blood cell count increased from 4400 to $23,000 / \mu \mathrm{L}$ and her temperature increased from 35.9 to $38.5^{\circ} \mathrm{C}$. The patient's abdominal pain also failed to improve. On the third day, the CT scan showed abdominal effusion and free air in the abdominal cavity (Fig. 1); she was diagnosed with a digestive tract perforation and peritonitis, and emergency surgery was performed. Intraoperatively, the perforation site was identified in the jejunum (about $30 \mathrm{~cm}$ anal-side to the Treitz ligament); the patient underwent a partial resection of the small intestine, and intraperitoneal irrigation was performed (Fig. 2).

The pathology of the jejunum showed a $35 \mathrm{~mm} \times 4$ $\mathrm{mm}$ ulcer and a 1-mm pinhole-shaped perforation site; infiltration of large atypical lymphocytes with small lymphocytes was observed around the perforated region (Fig. 3a-c). The immunohistochemical examination showed the expression of clusters of differentiation (CD) CD20, CD30, CD79a, and latent membrane protein 1 (LMP1) (Fig. 3d-f) and the absence of CD3, CD5, CD10, cyclinD1, cytokeratin AE1/AE3, or epithelial membrane antigen. LMP1 is a membrane protein produced by the Epstein-Barr virus (EBV), which is expressed in multiple EBV-related malignancies, including lymphomas [6, 7]. Therefore, these atypical lymphocytes were associated with diffuse large B cell lymphoma (DLBCL), a polymorphous type with Epstein-Barr virus-positive mucocutaneous ulcer (EBVMCU).

Due to the patient's pathological findings and history of RA treated with MTX, she was diagnosed as having Oii-LPD, specifically MTX-LPD, with a histological diagnosis of EBVMCU. MTX was no longer prescribed for the patient, but oral medication was resumed on day 12 , which included prednisolone $(5 \mathrm{mg} / 2.5 \mathrm{mg}$ every other 


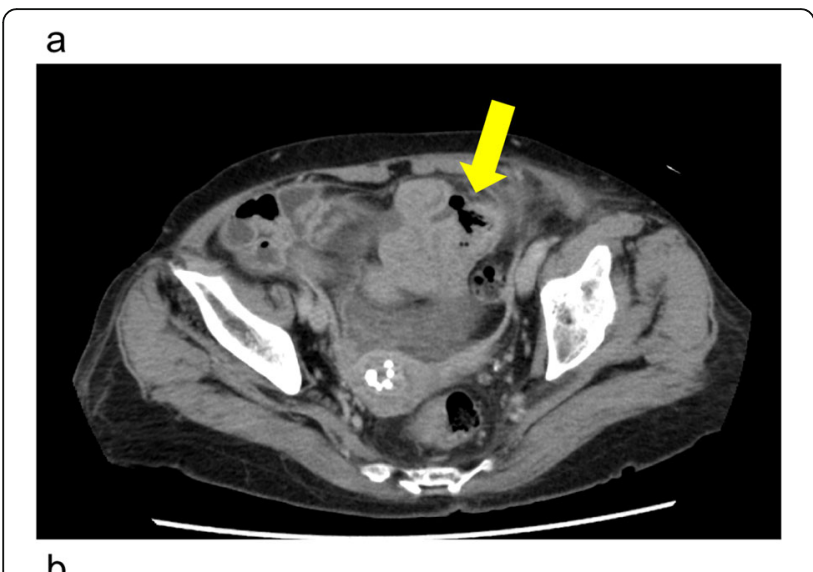

b

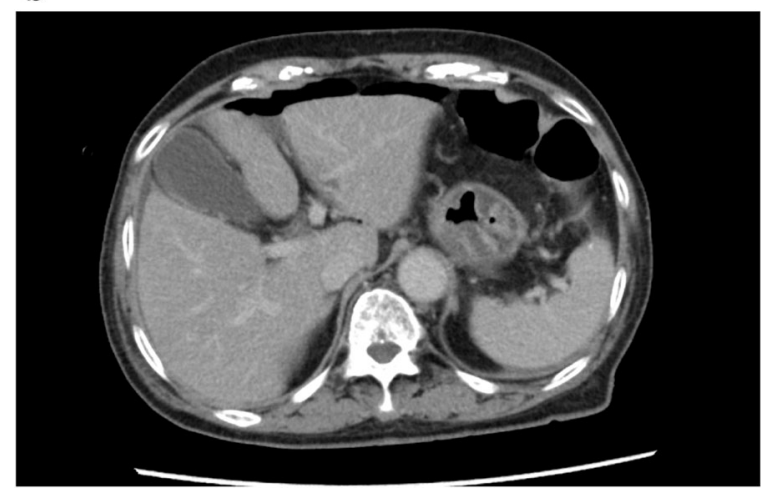

Fig. 1 Representative images of CT scan on hospital day 3. a Perforation site (arrow) of the small intestine and abdominal effusion. b Free air in the abdomen. CT computed tomography

day). The patient was discharged from the hospital on day 21, and positron emission tomography-computed tomography (PET-CT) was performed to evaluate the extent of the lymphoma, and it showed no findings associated with extranodal LPD.

One month after the patient had concluded her MTX treatment, her soluble interleukin-2 receptor (sIL-2R) levels had decreased from 1460 to $730 \mathrm{IU} / \mathrm{mL}$, and it was not necessary to initiate chemotherapy. One year later, her sIL-2R level was $<520 \mathrm{IU} / \mathrm{mL}$. The patient has continued to have a good course for 2 years after her hospitalization: she has remained asymptomatic, and her sIL-2R levels show no recurrence of MTX-LPD (Fig. 4). Her RA is controlled by bucillamine (200 mg per day) and iguratimod ( $25 \mathrm{mg}$ per day).

\section{Discussion and conclusions}

The causes for the perforation of the small intestine can be immune-mediated, infectious- or medication-related, congenital, metabolic, vascular, or neoplastic. Medication-related causes include non-steroidal antiinflammatory drugs; enteric-coated potassium chloride; chemotherapeutic agents, such as gefitinib and erlotinib and drug combinations containing etoposide and

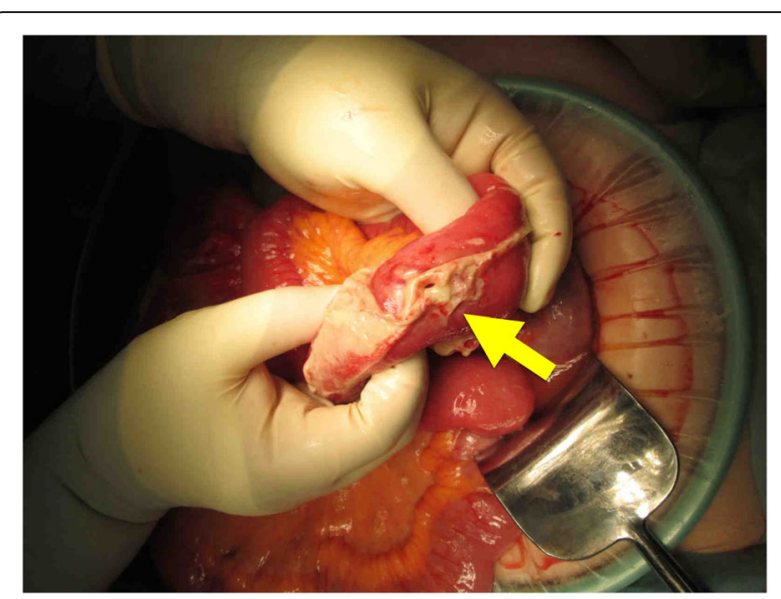

Fig. 2 Intraoperative findings revealed that the perforation site (arrow) was in the jejunum, about $30 \mathrm{~cm}$ anal-side to the Treitz ligament

cisplatin; and monoclonal antibodies, such as bevacizumab, IL-2, ipilimumab, and rituximab $[8,9]$. Monoclonal antibody therapeutics have been approved for several cancer and inflammatory diseases. Bevacizumab has been used in the treatment of metastatic colorectal cancer, metastatic non-small cell lung cancer, and other malignancies, including ovarian cancer, through the inhibition of vascular endothelial growth factor [9]. IL-2 has been used in patients with metastatic melanoma and renal cell carcinoma [8]. Ipilimumab is an antibody to cytotoxic $\mathrm{T}$ lymphocyte-associated antigen 4 that has been used in the treatment of metastatic melanoma and renal cell cancer [9]. Rituximab, an anti-CD20 monoclonal antibody, has been used to treat hematologic B cell malignancies, nephrotic syndrome, and rheumatoid arthritis $[9,10]$. Several side effects associated with the use of these monoclonal antibodies have been reported, with gastrointestinal perforations reported as the rare and common adverse effects [9-12] (Table 1). Malignant neoplasms (lymphomas, enteropathy-associated $\mathrm{T}$ cell lymphomas, adenocarcinomas, and carcinoid tumors) can also be a causative factor of small-intestine perforation [8]. One study showed that 92 of 1062 (9\%) patients with lymphoma involving the gastrointestinal tract developed a perforation [13], with large B cell lymphomas being the most common type.

Patients who have a therapy regimen that includes MTX can develop MTX-LPD, which can present as a benign lymphoid proliferation or malignant lymphoma. MTX-LPD is categorized as Oii-LPD by the WHO; this is a group of disorders defined as lymphoid proliferations or lymphomas that develop in patients receiving immunosuppressive drugs for autoimmune diseases or conditions other than in the post-transplant setting [14]. Extranodal lesions have been found in the digestive 

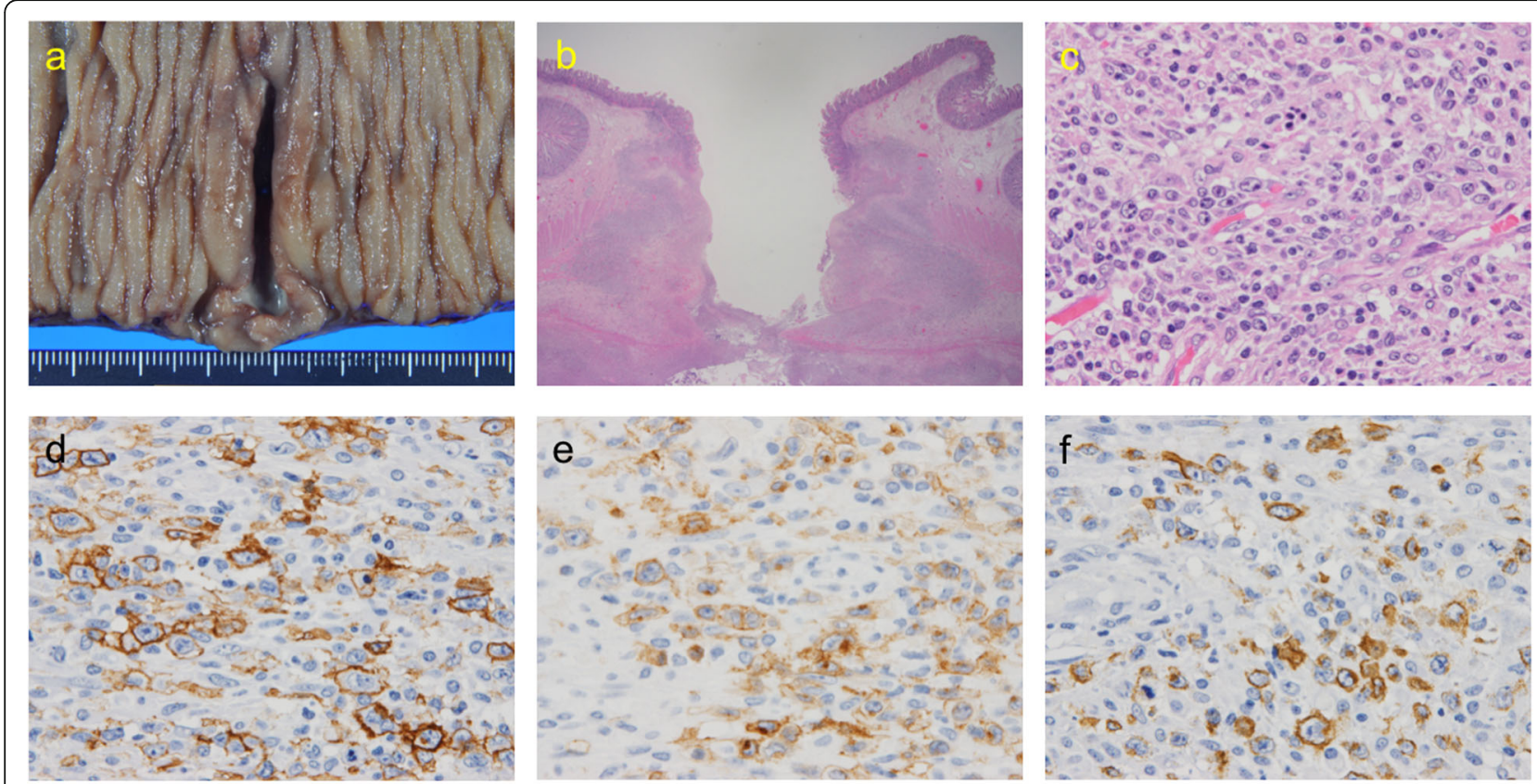

Fig. 3 a Macroscopically, a $35 \mathrm{~mm} \times 4 \mathrm{~mm}$ ulcer with a 1-mm perforation site in the jejunum. b Surgical specimens with perforated lesions from the ulcerated jejunum (hematoxylin and eosin staining, original magnification $\times 12.5$ ). c Infiltration of large atypical lymphocytes around the perforated region (hematoxylin and eosin $\times 600$ ). $\mathbf{d}$ Immunohistochemical staining of CD20. e Immunohistochemical staining of CD30. $\mathbf{f}$ Immunohistochemical staining of LMP-1 (c-f original magnification $\times 600$ ). CD cluster of differentiation, LMP-1 latent membrane protein 1

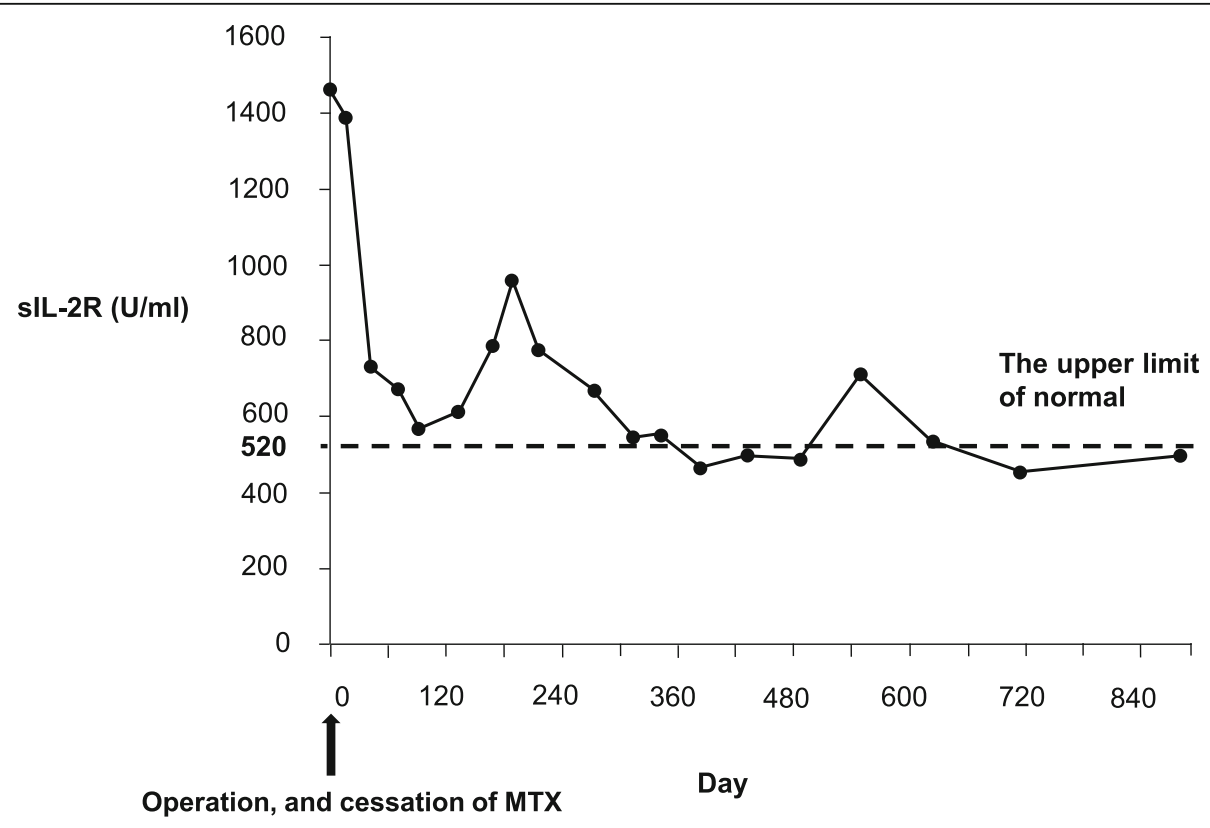

Fig. 4 A flow chart of the clinical course for methotrexate-associated lymphoproliferative disorders 
Table 1 Indications and side effects of using monoclonal antibodies

\begin{tabular}{|c|c|c|c|c|}
\hline $\begin{array}{l}\text { Monoclonal } \\
\text { antibody }\end{array}$ & Bevacizumab & Interleukin-2 & Ipilimumab & Rituximab \\
\hline Target & $\begin{array}{l}\text { Vascular endothelial growth } \\
\text { factor }\end{array}$ & Interleukin-2 receptor & $\begin{array}{l}\text { Cytotoxic T lymphocyte } \\
\text { antigen } 4\end{array}$ & CD20 antigen \\
\hline Indications & $\begin{array}{l}\text { Colorectal cancer, non-small cell } \\
\text { lung cancer, and ovarian cancer }\end{array}$ & Melanoma and renal cell cancer & $\begin{array}{l}\text { Melanoma and renal cell } \\
\text { cancer }\end{array}$ & $\begin{array}{l}\text { Hematologic B cell } \\
\text { malignancies, nephrotic } \\
\text { syndrome, and rheumatoid } \\
\text { arthritis }\end{array}$ \\
\hline Side effects & $\begin{array}{l}\text { Hypertension, proteinuria, } \\
\text { arterial thromboembolic events, } \\
\text { wound healing complications, } \\
\text { bleeding diathesis, and } \\
\text { gastrointestinal perforations }\end{array}$ & $\begin{array}{l}\text { Fever and chills, diarrhea, diffuse } \\
\text { erythroderma, hyperbilirubinemia, } \\
\text { anemia, thrombocytopenia, } \\
\text { eosinophilia, a capillary leak } \\
\text { syndrome, and intestinal } \\
\text { perforation }\end{array}$ & $\begin{array}{l}\text { Dermatitis, endocrinopathies, } \\
\text { particularly hypophysitis, uveitis, } \\
\text { nephritis, inflammatory } \\
\text { myopathies, hepatitis, colitis, } \\
\text { and intestinal perforation }\end{array}$ & $\begin{array}{l}\text { Fever and chills, } \\
\text { mucocutaneous reactions, fatal } \\
\text { infusion reactions, progressive } \\
\text { multifocal } \\
\text { leukoencephalopathy, and } \\
\text { intestinal perforation }\end{array}$ \\
\hline
\end{tabular}

CD20 cluster of differentiation 20

tracts of $4.1 \%$ of affected patients, and $1.4 \%$ had small intestinal lesions [15]. Small-intestine perforations due to MTX-LPD can occur but are extremely rare, with 7 cases reported in the Japanese literature and a single case reported in the English literature [4, 16] (Table 2). All cases were diagnosed as DLBCL, and association with EBV was observed in 5 cases. Spontaneous regression was achieved in 6 cases, and 7 cases have been reported to survive. However, a survival of $>2$ years was not reported in all cases. Considering the effect of MTX discontinuation on RA progression, we should follow up cautiously.

The occurrence of MTX-LPD correlates with the total dose and duration of MTX administration: the median interval between initiation of MTX treatment and the development of LPD was 30-54 months, and the median cumulative dose of MTX was 940-1500 mg [17, 18]. However, another study showed that the total dose and length of MTX administration were not associated with overall survival in patients with MTX-LPD [19]. In 18$45 \%$ of cases, spontaneous recovery from MTX-LPD takes place after MTX is discontinued [3, 19], often within 2-3 months [20]. If the LPD progresses after
MTX is discontinued or high sIL-2R levels persist, chemotherapy should be administered [20]. Our case achieved a disease regression without chemotherapy, although her cumulative dose $(3240 \mathrm{mg})$ and duration of MTX therapy (135 months) had been much greater than the median reported in previous studies $[17,18]$.

Large B cell lymphoma, including DLBCL, is the major histological subtype of MTX-LPD. Other frequent subtypes are reactive lymphoid hyperplasia, classic Hodgkin lymphoma, polymorphic B cell LPD, and indolent lymphoma which includes follicular lymphoma [21]. Some studies have shown that patients who are EBVpositive and non-DLBCL histological type have a high prevalence of spontaneous remission [22]. EBV-positive DLBCL is categorized as polymorphous lymphoma and large cell lymphoma subtypes, and a number of previous reports have revealed that the polymorphous lymphoma has a good prognosis than large cell lymphoma [23]. Additionally, some patients with EBV-positive LPD exhibited mucosal or cutaneous ulcers with polymorphous infiltration of small lymphocytes, immunoblasts, and atypical large lymphocytes, which are categorized as EBVMCU. EBVMCU is typically located in the

Table 2 Reported cases in Japan of perforation in the gastrointestinal tract caused by MTX-associated lymphoproliferative disorder

\begin{tabular}{|c|c|c|c|c|c|c|c|c|c|c|}
\hline Case & Year & Age & Sex & Organ & CD20 & EBV & Diagnosis & Operation & Chemotherapy & Prognosis \\
\hline 1 & 1995 & 73 & M & Ileum & Positive & Negative & $\mathrm{DLBCL}$ & Rt. hemicolectomy & No & Dead \\
\hline 2 & 2004 & 87 & $F$ & lleum & Positive & - & DLBCL & Partial resection & No & Alive \\
\hline 3 & 2006 & 63 & M & lleum & Positive & Positive & DLBCL & Ileo-cecum resection & No & Alive \\
\hline 4 & 2011 & 82 & F & Ileum & Positive & Positive & DLBCL & Ileo-cecum resection & $\mathrm{Yes}^{\mathrm{a}}$ & Alive \\
\hline 5 & 2016 & 70 & $\mathrm{~F}$ & Ileum & Positive & Positive & DLBCL & Rt. hemicolectomy & No & Alive \\
\hline 6 & 2017 & 77 & $F$ & lleum & Positive & Negative & DLBCL & Partial resection & No & Alive \\
\hline 7 & 2018 & 66 & F & Ileum & Positive & Positive & DLBCL & Partial resection & No & Alive \\
\hline 8 & 2020 & 62 & M & Jejunum & Positive & Positive & DLBCL & Partial resection & No & Alive \\
\hline Present case & 2020 & 81 & $\mathrm{~F}$ & Jejunum & Positive & Positive & EBVMCU & Partial resection & No & Alive \\
\hline
\end{tabular}

CD20 cluster of differentiation 20, EBV Epstein-Barr virus, DLBCL diffuse large B cell lymphoma, EBVMCU Epstein-Barr virus-positive mucocutaneous ulcer, Rt. hemicolectomy right hemicolectomy

${ }^{\mathrm{a} R}$-THP-COP 5course: rituximab (R), tetrahydropyranyl adriamycin (THP), cyclophosphamide (CPA), vincristine (VCR), and prednisolone (PSL) 
oropharynx, gastrointestinal tract, and skin [24]. Recent studies have reported that EBVMCU develops as OiiLPD induced by MTX treatment, and nearly all EBVMCU cases showed a favorable response to conservative management approaches such as the cessation of the MTX treatment for RA [25]. Although the detection rate of EBV is $5-10 \%$ in canonical LPD, the rate increases to $27 \%$ and $30-60 \%$ in patients with MTX-LPD and rheumatoid arthritis-associated LPD, respectively $[18,22]$. Among RA patients with EBV-positive MTXLPD, a lower incidence of DNA methylation in tumors and higher expression of tumor suppressor genes were observed. Although this may explain a higher probability of spontaneous LPD regression after MTX cessation in RA patients, the causal relationship between EBV and MTX-LPD is still unclear [22]. Another study reported that the tumor microenvironment with upregulation of autophagosome may support the development of EBVrelated LPD [26]. Our case had disease regression after she concluded MTX and underwent surgery for perforated jejunum. Because she had a spontaneous recovery from MTX-LPD, chemotherapy was not required; we consider that EBV-positivity played a role in the patient's spontaneous recovery.

In conclusion, we saw a rare case of jejunum perforation induced by EBV-related MTX-LPD. Since only a few similar cases have been reported, further research is necessary to evaluate the clinicopathological features. This case study shows that successful disease management and remission can be achieved by surgery and discontinuing MTX treatment; our case did not require chemotherapy. EBV-positive patients, especially those with a pathological presentation of EBVMCU, have a higher likelihood of remission, which may have influenced the successful outcome of the present case.

\section{Abbreviations \\ MTX: Methotrexate; RA: Rheumatoid arthritis; LPD: Lymphoproliferative disorders; MTX-LPD: Methotrexate-associated lymphoproliferative disorders; Oii-LPD: Other iatrogenic immunodeficiency-associated lymphoproliferative disorders; WHO: The World Health Organization; CT: Computed tomography; CD: Cluster of differentiation; LMP-1: Latent membrane protein 1; EBV: Epstein-Barr virus; DLBCL: Diffuse large B cell lymphoma; EBVMCU: Epstein-Barr virus-positive mucocutaneous ulcer; PET-CT: Positron emission tomography-computed tomography; slL-2R: Soluble interleukin-2 receptor}

\section{Acknowledgements}

This work was supported in part by Grants-in-Aid for Research from the National Center for Global Health and Medicine (20A 3001).

\section{Authors' contributions}

$\mathrm{MN}$ and RS wrote the paper; $\mathrm{HO}, \mathrm{TN}, \mathrm{KK}, \mathrm{AS}, \mathrm{DE}$, and NA contributed to the paper design and coordination. All authors have read and approved the manuscript.

\section{Funding}

None.
Availability of data and materials

Not applicable.

\section{Ethics approval and consent to participate}

Written consent was obtained from the patient. As this is a case report, approval from the institutional review board was not needed.

\section{Consent for publication}

Written informed consent was obtained from the patient for the publication of this report and any accompanying images.

\section{Competing interests}

The authors declare that they have no competing interests.

Received: 12 October 2020 Accepted: 16 December 2020

Published online: 02 January 2021

\section{References}

1. Yoshida Y, Takahashi Y, Yamashita H, Kano T, Kaneko H, Mimori A. Clinical characteristics and incidence of methotrexaterelated lymphoproliferative disorders of patients with rheumatoid arthritis. Mod Rheumatol. 2014;24: 763-5.

2. Swerdlow SH, Campo E, Harris NL, Jaffe ES, Pileri SA, Stein H, et al. World Health Organization classification of tumours of haematopoietic and lymphoid tissues. Revised 4th ed. Lyon: IARC Press; 2017.

3. Gion Y, Iwaki N, Takata K, Takeuchi M, Nishida K, Orita Y, et al. Clinicopathological analysis of methotrexate-associated lymphoproliferative disorders: comparison of diffuse large B-cell lymphoma and classical Hodgkin lymphoma types. Cancer Sci. 2017;108:1271-80.

4. Oe S, Yamaoka R, Furumoto K, Yamaguchi M. Jejunum perforation caused by malignant lymphoma following methotrexate therapy for rheumatoid arthritis. Jpn J Gastroenterol Surg. 2020;53:239-45.

5. Takanashi S, Aisa Y, Ito C, Arakaki H, Osada Y, Amano Y, et al. Clinical characteristics of methotrexate-associated lymphoproliferative disorders: relationship between absolute lymphocyte count recovery and spontaneous regression. Rheumatol Int. 2017;37:1629-33.

6. Houldcroft CJ, Kellam P. Host genetics of Epstein-Barr virus infection, latency and disease. Rev Med Virol. 2015;25:71-84.

7. Wang LW, Jiang S, Gewurz BE. Epstein-Barr virus LMP1-mediated oncogenicity. J Virol. 2017;91:e01718-6.

8. Freeman $\mathrm{HJ}$. Spontaneous free perforation of the small intestine in adults, World J Gastroenterol. 2014;20:9990-7.

9. Freeman HJ. Colitis associated with biological agents. World J Gastroenterol. 2012;18:1871-4.

10. Salles G, Barrett M, Foà R, Maurer J, O'Brien S, Valente N, et al. Rituximab in B-cell hematologic malignancies: a review of 20 years of clinical experience. Adv Ther. 2017;34:2232-73.

11. Lecarpentier E, Ouaffi L, Mir O, Berveiller P, Maurel M, Pujade-Lauraine E, et al. Bevacizumab-induced small bowel perforation in a patient with breast cancer without intraabdominal metastases. Invest New Drugs. 2011;29: 1500-3.

12. Klempner MS, Noring R, Mier JW, Atkins MB. An acquired chemotactic defect in neutrophils from patients receiving interleukin-2 immunotherapy. N Engl J Med. 1990;322:959-65.

13. Vaidya R, Habermann TM, Donohue JH. Bowel perforation in intestinal lymphoma: incidence and clinical features. Ann Oncol. 2013;24:2439-43.

14. Tokuhira M, Tamaru J, Kizaki M. Clinical management for other iatrogenic immunodeficiency-associated lymphoproliferative disorders. J Clin Exp Hematop. 2018:59:72-92.

15. Kurita D, Miyoshi H, Ichikawa A, Kato K, Imaizumi Y. Seki, et al. Methotrexateassociated lymphoproliferative disorders in patients with rheumatoid arthritis: clinicopathologic features and prognostic factors. Am J Surg Pathol. 2019:43:869-84.

16. Suzuki E, Kanno T, Kimura S, Irie T, Odajima H, Migita K, et al. Methotrexateassociated lymphoproliferative disorder complicated by severe acute respiratory failure and ileal perforation: a case report. Fukushima J Med Sci. 2018;64:82-8.

17. Salloum E, Cooper DL, Howe G, Lacy J, Tallini G, Crouch J, et al. Spontaneous regression of lymphoproliferative disorders in patients treated with methotrexate for rheumatoid arthritis and other rheumatic diseases. J Clin Oncol. 1996;14:1943-9. 
18. Hoshida Y, Xu JX, Fujita S, Nakamichi I, Ikeda J, Tomita Y, et al. Lymphoproliferative disorders in rheumatoid arthritis: clinicopathological analysis of 76 cases in relation to methotrexate medication. J Rheumatol. 2007:34:322-31.

19. Ichikawa A, Arakawa F, Kiyasu J, Sato K, Miyoshi H, Niino D, et al. Methotrexate/iatrogenic lymphoproliferative disorders in rheumatoid arthritis: histology, Epstein-Barr virus, and clonality are important predictors of disease progression and regression. Eur J Haematol. 2013;91:20-8.

20. Rizzi R, Curci P, Delia M, Rinaldi E, Chiefa A, Specchia G, et al. Spontaneous remission of "methotrexate-associated lymphoproliferative disorders" after discontinuation of immunosuppressive treatment for autoimmune disease. Review of the literature. Med Oncol. 2008;26:1-9.

21. Momose S, Tamaru J. latrogenic immunodeficiency-associated lymphoproliferative disorders of B-cell type that develop in patients receiving immunosuppressive drugs other than in the post-transplant setting. J Clin Exp Hematop. 2019;59:48-55.

22. Saito S, Takeuchi T. Immune response in LPD during methotrexate administration (MTX-LPD) in rheumatoid arthritis patients. J Clin Exp Hematop. 2019;59:145-55.

23. Oyama T, Ichimura $K$, Suzuki R, Suzumiya J, Ohshima $K$, Yatabe $Y$, et al. Senile EBV+ B-cell lymphoproliferative disorders: a clinicopathologic study of 22 patients. Am J Surg Pathol. 2003:27:16-26.

24. Roberts TK, Chen X, Liao JJ. Diagnostic and therapeutic challenges of EBVpositive mucocutaneous ulcer: a case report and systematic review of the literature. Exp Hematol Oncol. 2016;5:13.

25. Ikeda T, Gion Y, Yoshino T, Sato Y. A review of EBV-positive mucocutaneous ulcers focusing on clinical and pathological aspects. J Clin Exp Hematop. 2019:59:64-71

26. Jantuan E, Chiu B, Chiu B, Shen F, Oudit GY, Sergi C. The tumo microenvironment may trigger lymphoproliferation in cardiac myxoma. Transl Oncol. 2020;14:100911.

\section{Publisher's Note}

Springer Nature remains neutral with regard to jurisdictional claims in published maps and institutional affiliations.

Ready to submit your research? Choose BMC and benefit from:

- fast, convenient online submission

- thorough peer review by experienced researchers in your field

- rapid publication on acceptance

- support for research data, including large and complex data types

- gold Open Access which fosters wider collaboration and increased citations

- maximum visibility for your research: over $100 \mathrm{M}$ website views per year

At $\mathrm{BMC}$, research is always in progress.

Learn more biomedcentral.com/submissions 